\title{
Introduction: co-evolution and complex adaptive systems in evolutionary economics
}

\author{
John Foster • Andreas Pyka
}

Published online: 11 February 2014

(C) Springer-Verlag Berlin Heidelberg 2014

The theme of the $14^{\text {th }}$ International Joseph A. Schumpeter Conference, held from July 2 nd $-5^{\text {th }} 2012$, was "the evolution of economic systems, through innovation, entrepreneurship and competitive processes." This was intended to be broad enough to encompass a wide range of submitted papers in evolutionary economics and related areas. However, perhaps more than in previous conferences, there was a focus upon viewing economic evolution from the perspective of complex systems science, suitably defined for application in economic contexts. This reflected the ongoing interest in complex economic systems that had existed at the University of Queensland for two decades. Some will remember the first 'Brisbane Club' international workshop on this perspective on evolutionary economics at UQ in 1999 and the resultant volume edited by Foster and Metcalfe in 2001. Although having the Schumpeter Conference in Brisbane was viewed by many of us as a fitting conclusion to the Brisbane Club series of meetings, the Club met once again in Vienna in 2013 thanks to excellent efforts of Kurt Dopfer. However, the 2012 Schumpeter Conference was much more than just an extension of this tradition. As with previous conferences, a very diverse range of research questions were addressed and they stimulated robust discussion and debate. The vibrancy and relevance of modern research in evolutionary was there for all to see and this was in no small measure due to the high proportion of early career researchers presenting at the Conference.

The five plenary sessions dealt with: Asian emergence -causes and consequences; innovation policy-evolutionary economic perspectives; knowledge, entrepreneurship and the evolution of markets; modelling macroeconomic behaviour when economic systems are recognised as complex; neo-Schumpeterian evolutionary economics-where has it been going and what is its future? We were very privileged to be able to listen to the following invited speakers: Peter Allen, Ping Chen, Terry Cutler, Giovanni Dosi; Alan Hughes, David Lane, Keun Lee, Deirdre McCloskey, Stan Metcalfe, Jason Potts and Ulrich Witt.

J. Foster

University of Queensland, Brisbane, Australia

A. Pyka $(\bowtie)$

University of Hohenheim, Stuttgart, Germany

e-mail: a.pyka@uni-hohenheim.de 
There were 61 parallel sessions including: finance and innovation; economic growth; energy and economic evolution; the evolution of the firm; managing innovation; education and innovation; technological paradigms and evolution; Schumpeter revisited; industry linkages; patents; energy innovation-corporate strategy; demand and consumption; evolutionary perspectives on 'knowledge'; productivity growth; energy innovation-policy; innovation networks; spillovers; innovation case studies; advances in evolutionary economic theory; long waves, finance and global crisis; behavioral perspectives on economic evolution; Chinese economic development; climate change policy; patents, startups and disruption; complex systems; catch up; overcoming socio-cultural obstacles to innovation; new ventures; evolution of the 'green economy'; East Asian growth; spin-offs; innovation policy; emergence in complex economic systems; spatial perspectives on economic evolution; innovation and firm performance; entrepreneurship; energy and green innovation; political economy, law and innovation; history-friendly modeling; the labor market; competition and selection; advances in evolutionary modeling; university-industry collaboration; persistence, inertia and path dependence; complex evolving networks; research collaboration and the emergence of capabilities; human capital; absorptive capacity; developmentindustrialization; international collaboration on innovation; health; technological spillovers.

This special issue is both the outcome of a strong competition among the papers submitted after the conference and the result of a thematic focus of the editors on a core issue of evolutionary economics namely co-evolution and complex adaptive systems. The contributions selected show the scope of analysis in evolutionary economics as well as the explanatory power with respect to economic dynamics and long term economic development.

The special issue starts with John Foster's Presidential Address entitled "Energy, Knowledge and Economic Growth" and views economic growth as a self-organized process with energy use and new knowledge associated with energy use as major co-evolutionary drivers. Ping Chen's contribution "Metabolic Growth Theory: Market-Share Competition, Learning Uncertainty, and Technology Wavelets" focusses on the trade-off between stability and complexity of an ecological-industrial system. His growth and technological development theory allows for non-linear economic development in waves combining the thinking of Adam Smith, Thomas Robert Malthus and Joseph Alois Schumpeter. Peter Allen's contribution "Evolution, Complexity, Uncertainty and Innovation" introduces to the varieties of complex systems, the required assumptions and limitations and most important to their explanatory power for economic reasoning. Esben Sloth Andersen and Jakob Rubaek Holm focus on the varieties of selection processes responsible for economic evolution. In their contribution "The Signs of Change in Economic Evolution" they differ between three selection mechanisms they label intentional, stabilizing and diversifying selection and explain the meaning of each selection mechanism for economic evolution. Felix Munoz and MariaIsabel Encinar highlight the interaction of agents' intentions for emergent phenomena in economic evolution. Their contribution "Intentionality and the Emergence of Complexity: an Analytical Approach" complements Andersen's and Holm's reflections on selection mechanisms by proposing an analytical approach based on agents' action plans to explain emerging patterns in economic behavior.

Compared to the previous contributions the following five papers choose more applied questions or address central issues in an evolutionary innovation-driven economic development. In the paper "Property Rights as a Complex Adaptive System: How Entrepreneurship transforms Intellectual Property Structures" David Harper treats intellectual property rights as a complex adaptive system which offers entrepreneurs opportunities and which is changed by entrepreneurial actions. These feedback effects determine meso-levels as 
structures within the macro intellectual property rights. Peter Hall's and Robert Wylie's contribution entitled "Isolation and Technological Innovation" analyze conditions for disruptive change in technological evolution stemming from isolation and introduce to two cases of military innovations to illustrate their reasoning. To address issues of economic welfare is one of the major difficulties in evolutionary economics. In his contribution entitled "Towards a General Model of the Innovation-Subjective Well-Being Nexus" Hans-Jürgen Engelbrecht introduces the concept of procedural utility to overcome the difficulties in addressing welfare issues stemming from uncertainty and dynamics inherent to innovation processes. Abiodun Egbetokun and Ivan Savin pick up an old question in innovation economics: why do firms cooperate in innovation if they run into danger to lose knowledge to potential competitors? Their contribution "Absorptive Capacity and Innovation: When is it Better to Cooperate?" introduces to a new model which focuses on knowledge distances, voluntary and involuntary spillovers as well as the required investments to integrate external knowledge. The last contribution of this special issue "Innovation and Finance: a Stock Flow Consistent-Analysis of Great Surges of Development" by Alessandro Caiani and Antoine Godin links Neo-Schumpeterian and Post-Keynesian approaches to analyze the finance-innovation nexus which allows to explain the co-evolutionary relationship between technological change, demand and finance acknowledging for structural changes.

All contributions to this special issue join the focus on complex adaptive systems as an adequate framework for economic analysis. The contributions make clear how far the evolutionary complex methodology is developed and how rich the explanatory power of economic analysis can be with the right instruments: Changes of the system like innovationdriven economic development or economic crisis become endogenous phenomena which can be analyzed immediately without exogenous shocks and/or the application of restrictive assumptions. 